\title{
Durable change in glycaemic control following intensive management of type 2 diabetes in the ACCORD clinical trial
}

\author{
Zubin Punthakee • Michael E. Miller • Debra L. Simmons • Matthew C. Riddle • \\ Faramarz Ismail-Beigi • David J. Brillon • Richard M. Bergenstal • Peter J. Savage • \\ Irene Hramiak • Joseph F. Largay • Ajay Sood • Hertzel C. Gerstein • \\ for the ACCORD Group of Investigators
}

Received: 29 March 2014 / Accepted: 9 June 2014 /Published online: 2 July 2014

(C) Springer-Verlag Berlin Heidelberg 2014

\begin{abstract}
Aims/hypothesis We aimed to determine the persistence of glycaemic control 1 year after a limited period of intensive glycaemic management of type 2 diabetes.

Methods 4119 ACCORD Trial participants randomised to target $\mathrm{HbA}_{1 \mathrm{c}}<6.0 \%$ (42 $\mathrm{mmol} / \mathrm{mol}$ ) for $4.0 \pm 1.2$ years were systematically transitioned to target $\mathrm{HbA}_{1 \mathrm{c}} 7.0-7.9 \%$ (53-63 mmol/mol) and followed for an additional $1.1 \pm 0.2$ years. Characteristics of participants with $\mathrm{HbA}_{1 \mathrm{c}}<6.5 \%(48 \mathrm{mmol} / \mathrm{mol})$ or $\geq 6.5 \%$ at transition were compared. Changes in BMI and glucose-lowering
\end{abstract}

Electronic supplementary material The online version of this article (doi:10.1007/s00125-014-3318-5) contains peer-reviewed but unedited supplementary material, which is available to authorised users.

\section{Z. Punthakee $(\bowtie) \cdot$ H. C. Gerstein}

Department of Medicine, McMaster University, 1280 Main St W.,

Hamilton, ON L8S 4K1, Canada

e-mail: zubin.punthakee@mcmaster.ca

\section{E. Miller}

Department of Biostatistical Sciences, Division of Public Health

Sciences, Wake Forest University, Winston-Salem, NC, USA

\section{L. Simmons}

Division of Endocrinology, Department of Internal Medicine,

School of Medicine, University of Utah,

Salt Lake City, UT, USA

\section{L. Simmons}

VA Salt Lake City Health Care System, Salt Lake City, UT, USA

\section{C. Riddle}

Division of Endocrinology, Diabetes \& Clinical Nutrition, Oregon

Health \& Science University, Portland, OR, USA

F. Ismail-Beigi $\cdot A$. Sood

Department of Medicine, Case Western Reserve University,

Cleveland, $\mathrm{OH}$, USA medications were compared between those ending with $\mathrm{HbA}_{1 \mathrm{c}}<6.5 \%$ vs $\geq 6.5 \%$. Poisson models were used to assess the independent effect of attaining $\mathrm{HbA}_{1 \mathrm{c}}<6.5 \%$ before transition on ending with $\mathrm{HbA}_{1 \mathrm{c}}<6.5 \%$.

Results Participants with pre-transition $\mathrm{HbA}_{1 \mathrm{c}}<6.5 \%$ were older with shorter duration diabetes and took less insulin but more non-insulin glucose-lowering agents than those with higher $\mathrm{HbA}_{1 \mathrm{c}}$. A total of 823 participants achieved a final $\mathrm{HbA}_{1 \mathrm{c}}<6.5 \%$, and had greater post-transition reductions in $\mathrm{BMI}$, insulin dose and secretagogue and acarbose use than those with higher $\mathrm{HbA}_{1 \mathrm{c}}(p<0.0001) . \mathrm{HbA}_{1 \mathrm{c}}<6.5 \%$ at

\section{F. Ismail-Beigi}

Cleveland VA Medical Center, Cleveland, OH, USA

D. J. Brillon

Division of Endocrinology, Weill Cornell Medical College of Cornell University, New York, NY, USA

R. M. Bergenstal

International Diabetes Center at Park Nicollet, Minneapolis, MN, USA

\section{P. J. Savage}

National Institute of Diabetes and Digestive and Kidney Diseases,

National Institutes of Health, Bethesda, MD, USA

I. Hramiak

Department of Medicine, Western University, London, ON, Canada

\section{J. F. Largay}

Division of Endocrinology, Department of Medicine,

University of North Carolina, Chapel Hill, NC, USA

A. Sood

Louis Stokes VA Medical Center, Cleveland, OH, USA 
transition predicted final $\mathrm{HbA}_{1 \mathrm{c}}<6.5 \%$ (crude RR $4.9[95 \%$ CI 4.0, 5.9]; RR 3.9 [95\% CI 3.2, 4.8] adjusted for demographics, co-interventions, pre-intervention $\mathrm{HbA}_{1 \mathrm{c}}$, BMI and glucose-lowering medication, and post-transition change in both BMI and glucose-lowering medication). Progressively lower pre-transition $\mathrm{HbA}_{1 \mathrm{c}}$ levels were associated with a greater likelihood of maintaining a final $\mathrm{HbA}_{1 \mathrm{c}}$ of $<6.5 \%$. Follow-up duration was not associated with post-transition rise in $\mathrm{HbA}_{1 \mathrm{c}}$.

Conclusions/interpretation Time-limited intensive glycaemic management using a combination of agents that achieves $\mathrm{HbA}_{1 \mathrm{c}}$ levels below $6.5 \%$ in established diabetes is associated with glycaemic control more than 1 year after therapy is relaxed.

Keywords Intensive glucose lowering - Long-term glycaemic control - Post-intervention follow-up - Type 2 diabetes

$\begin{array}{ll}\text { Abbreviations } \\ \text { ACCORD } & \begin{array}{l}\text { Action to Control Cardiovascular Risk in } \\ \text { Diabetes }\end{array} \\ \text { CDE } & \text { Certified diabetes educator } \\ \text { SMBG } & \text { Self-monitoring of blood glucose }\end{array}$

\section{Introduction}

Type 2 diabetes is generally regarded as a slowly progressive disease characterised by a reduction in ability to maintain glucose homeostasis over time [1] and a concomitant increase in the need for pharmacological therapy to do so. Recent observations that bariatric surgery seems to slow or even reverse this process $[2,3]$ suggest that diabetes is not necessarily progressive and that beta cell function and the capacity to make insulin can be improved $[4,5]$ in association with reduced body mass and food intake. Additional evidence suggests that short-term intensive insulin therapy early in the course of diabetes [6] plus lifestyle modification [7] may have persistent effects on glycaemic control by reducing the demand on the beta cells to secrete insulin, thereby preserving their function $[8,9]$, or by improving adherence to healthpromoting behaviours. Other agents, including thiazolidinediones and incretin mimetics, also improve beta cell function $[8,9]$. It is not known whether a strategy of prolonged multimodal intensive glucose lowering has durable effects.

The Action to Control Cardiovascular Risk in Diabetes (ACCORD) Trial (NCT00000620) was designed to study the cardiovascular effects of intensive glycaemic control, intensive blood pressure control, and fibrate use among people with type 2 diabetes. As previously reported [10], the intensive glycaemic intervention was discontinued after the independent data and safety monitoring board noted excess mortality in that group. As a result, participants who had been randomised to intensive glycaemic management (i.e. targeting an $\mathrm{HbA}_{1 \mathrm{c}}$ of $<6.0 \%$ [42 $\left.\mathrm{mmol} / \mathrm{mol}\right]$ ) and who, as a group, had reduced their entry median $\mathrm{HbA}_{1 \mathrm{c}}$ from $8.1 \%$ (65 mmol $/ \mathrm{mol}$ ) to $6.4 \%(46 \mathrm{mmol} / \mathrm{mol})$ were all transitioned to the standard glycaemic management strategy (i.e. targeting an $\mathrm{HbA}_{1 \mathrm{c}}$ of $7.0-7.9 \%$ [53-63 mmol $/ \mathrm{mol}]$ ), and continued to be followed until the blood pressure and lipid trials that were part of the initial ACCORD design were completed about 1 year later. By the end of the follow-up period, the $\mathrm{HbA}_{1 \mathrm{c}}$ in this group was $7.4 \pm 1.2 \%$ compared with $7.8 \pm 1.2 \%$ in the group randomised to standard care [11]. This situation offered a unique opportunity to observe the glycaemic effects of intentional relaxation of glycaemic therapy in a group of patients who started out with poorly controlled $\left(\mathrm{HbA}_{1 \mathrm{c}}>7.5 \%\right.$ [58 $\left.\left.\mathrm{mmol} / \mathrm{mol}\right]\right)$, longstanding (median 10 years) type 2 diabetes, and who achieved near-normal $\mathrm{HbA}_{1 \mathrm{c}}$ levels during more than 3 years of intensive glucose lowering. This report therefore describes the metabolic course of participants randomised to the intensive glycaemia group who had at least one visit before transition and one visit after transition to a standard glycaemic management approach, and determines whether a period of intensive glucose lowering that achieved normal or nearnormal glucose levels is associated with persistence of glycaemic control after relaxation of therapy.

\section{Methods}

ACCORD Trial The design of the ACCORD Trial has been described previously $[12,13]$. Briefly, 10,251 participants aged 40-79 years with type 2 diabetes, an $\mathrm{HbA}_{1 \mathrm{c}} \geq 7.5 \%$ and additional cardiovascular risk factors were recruited at 77 sites in North America. Participants were randomised to either intensive glycaemic management targeting an $\mathrm{HbA}_{1 \mathrm{c}}$ of $<6.0 \%$ or standard glycaemic management targeting an $\mathrm{HbA}_{1 \mathrm{c}}$ of $7.0-7.9 \%$. In a double $2 \times 2$ factorial design, 4,733 participants were also randomised to either intensive blood pressure lowering $(<120 / 80 \mathrm{mmHg})$ or standard blood pressure lowering (130-139/80-90 $\mathrm{mmHg}$ ), and the remaining 5,518 participants were randomised to the addition of fenofibrate or placebo to statin therapy. The trial was approved by ethics committees at all participating sites, and all participants gave informed consent.

The intensive glycaemic management strategy targeting an $\mathrm{HbA}_{1 \mathrm{c}}$ of $<6.0 \%$ involved monthly visits for the first 4 months followed by visits every 1-2 months, which included review of logs of self-monitoring of blood glucose (SMBG; performed two to eight times per day) and point-of-care $\mathrm{HbA}_{1 \mathrm{c}}$ (every 2 months), review and prescription or titration of glucose-lowering medication from all approved classes in 
any combination to further lower $\mathrm{HbA}_{1 \mathrm{c}}$ if it could be achieved safely while avoiding hypoglycaemia, and education regarding diabetes self-management including diet, physical activity, insulin self-titration, hypoglycaemia avoidance and management, with additional supportive phone calls between visits.

The standard management strategy targeting an $\mathrm{HbA}_{1 \mathrm{c}}$ of 7.0-7.9\% included visits every 4 months (except for participants also randomised to intensive blood pressure control, who had visits every 2 months) to review logs of SMBG (performed a few times per week to three times per day), education regarding diabetes self-management as needed, and review and prescription or titration of glucose-lowering medication including down-titration for any of the following reasons: severe or frequent symptomatic hypoglycaemia; $50 \%$ or more SMBG values below $5 \mathrm{mmol} / \mathrm{l}(90 \mathrm{mg} / \mathrm{dl})$; or in the setting of either one $\mathrm{HbA}_{1 \mathrm{c}}<6.5 \%$ or consecutive $\mathrm{HbA}_{1 \mathrm{c}}$ values $<7.0 \%$, any of use of insulin or a secretagogue, any symptomatic hypoglycaemia or any SMBG below $5 \mathrm{mmol} / \mathrm{l}$ (90 mg/dl).

An extra visit was scheduled for all intensive group participants at the time of the transition to explain the new $\mathrm{HbA}_{1 \mathrm{c}}$ goal of $7.0-7.9 \%$, and their conversion to the standard management strategy of the trial as described above. At this transition visit, research staff reviewed SMBG values, pointof-care $\mathrm{HbA}_{1 \mathrm{c}}$ and medications, and down-titrated medications for individuals with an $\mathrm{HbA}_{1 \mathrm{c}}<7.0 \%$.

Glucose-lowering medications, BMI and a centrally measured $\mathrm{HbA}_{1 \mathrm{c}}$ were documented prior to randomisation and at least every 4 months for all participants throughout the study. Glycaemic status of all participants was reviewed centrally and reported to investigators regularly to promote adherence to the standard glycaemic management strategy after transition. In particular, site investigators were sent regular reminders of the down-titration algorithm, reports indicating the proportion of formerly intensive group participants at their site whose medications were down-titrated according to the standard management algorithm, and listings of intensive group participants whose $\mathrm{HbA}_{1 \mathrm{c}}$ remained $<7.0 \%$. Extra visits or phone calls were completed to further down-titrate glucose-lowering medications as needed to achieve an $\mathrm{HbA}_{1 \mathrm{c}}$ of $7.0-7.9 \%$.

The last study visit on or before the date of the transition at which $\mathrm{HbA}_{1 \mathrm{c}}$ was measured centrally was considered the pretransition visit, and pre-transition values were obtained from that visit. Thereafter, the last study visit at which $\mathrm{HbA}_{1 \mathrm{c}}$ was measured centrally was considered the final post-transition visit, and post-transition values were obtained from that visit.

Participants All participants allocated to the intensive group who were alive at the time of transition and who had at least one $\mathrm{HbA}_{1 \mathrm{c}}$ measurement at or before the date of transition and at least one measurement after the transition date were included in this analysis.
Statistical methods All analyses were conducted using SAS software version 9.1 (SAS Institute, Cary, NC, USA). Twosided $p$ values $<0.05$ were considered nominally significant. Before any analyses were conducted, a decision was made to assess the effect of achieving a pre-transition $\mathrm{HbA}_{1 \mathrm{c}}<6.5 \%$ on the final $\mathrm{HbA}_{1 \mathrm{c}}$ level. This threshold was chosen because it was just above the median $\mathrm{HbA}_{1 \mathrm{c}}$ level achieved in the intensive group during the ACCORD Trial (i.e. 6.4\%) and thus represented approximately half of the intensive group participants. It is also the threshold used to diagnose diabetes [14].

Characteristics of intensive group participants whose last pre-transition $\mathrm{HbA}_{1 \mathrm{c}}$ was $<6.5 \% \mathrm{vs} \geq 6.5 \%$ were compared by $t$ tests or $\chi^{2}$ tests. Mean insulin doses were calculated based on all participants; those not on insulin were assigned a dose of 0 units for the analyses. Participants whose final post-transition $\mathrm{HbA}_{1 \mathrm{c}}$ was $<6.5 \%$ vs $\geq 6.5 \%$ were compared for mean final $\mathrm{HbA}_{1 \mathrm{c}}$, post-transition change in BMI (three categories), change in insulin dose (three categories), and change in use of other glucose-lowering medications (added, continued, never prescribed or discontinued for each medication class) by $\chi^{2}$ tests.

RRs with $95 \%$ CI of achieving a final post-transition $\mathrm{HbA}_{1 \mathrm{c}}<6.5 \%$ were calculated for a pre-transition $\mathrm{HbA}_{1 \mathrm{c}}$ $<6.5 \%$ vs $\geq 6.5 \%$ using Poisson regression, both before and after adjustment for baseline pre-randomisation $\mathrm{HbA}_{1 \mathrm{c}}$ and demographic, anthropometric, co-interventional and pharmacological covariates listed in Tables 1 and 2. To assess the relationship between the pre-transition and final $\mathrm{HbA}_{1 \mathrm{c}}$ levels, RRs were calculated for $0.1 \%$ increments of the pre-transition $\mathrm{HbA}_{1 \mathrm{c}}$ level. Comparisons were relative to those who had a pre-transition $\mathrm{HbA}_{1 \mathrm{c}}$ equal to $6.5 \%$ using unadjusted and adjusted Poisson regression. Lines were fitted assuming a single linear term for pre-transition $\mathrm{HbA}_{1 \mathrm{c}}$ in a log-linear model. Finally, to determine if $\mathrm{HbA}_{1 \mathrm{c}}$ levels 'drifted' up with a greater duration of exposure to the standard glycaemic intervention after transition, a second degree penalised Bspline was fitted for change in $\mathrm{HbA}_{1 \mathrm{c}}$ vs time between pretransition and final $\mathrm{HbA}_{1 \mathrm{c}}$ measurements [15].

\section{Results}

A total of 4,119 participants who were allocated to intensive glycaemic management and who had at least one $\mathrm{HbA}_{1 \mathrm{c}}$ level measured before and after transition to the approach used in the standard glycaemic group were analysed. Excluded intensive group participant characteristics are summarised in the electronic supplementary material (ESM) Table 1 for comparison. The mean $\pm \mathrm{SD}$ duration of intensive glycaemic management in the pre-transition period was $4.0 \pm 1.2$ years (range 2.3-7.0). As noted in Table 1, compared with the 1,786 intensive group participants whose $\mathrm{HbA}_{1 \mathrm{c}}$ before transition 
Table 1 Baseline and pre-transition characteristics of intensive group participants who were transitioned to standard care and followed-up after transition
Values are expressed as $n(\%)$ or mean \pm SD

${ }^{\mathrm{a}}$ Includes those with at least one visit after transition

${ }^{\mathrm{b}}$ Includes those taking $0 \mathrm{U}$

\begin{tabular}{|c|c|c|c|}
\hline Characteristic & $\begin{array}{l}\text { Last } \mathrm{HbA}_{1 \mathrm{c}} \text { before } \\
\text { transition }<6.5 \% \\
\left(n=2,333^{\mathrm{a}}\right)\end{array}$ & $\begin{array}{l}\text { Last } \mathrm{HbA}_{1 \mathrm{c}} \text { before } \\
\text { transition } \geq 6.5 \% \\
\left(n=1,786^{\mathrm{a}}\right)\end{array}$ & $p$ value \\
\hline Female & $843(36.1)$ & $732(41.0)$ & 0.002 \\
\hline Randomised to receive fibrate & $628(26.9)$ & $475(26.6)$ & 0.8 \\
\hline Randomised to intensive BP control & $511(21.9)$ & $410(23.0)$ & 0.4 \\
\hline CDE availability at site & $976(41.8)$ & $662(37.1)$ & 0.002 \\
\hline \multicolumn{4}{|l|}{ At randomisation } \\
\hline $\mathrm{HbA}_{1 \mathrm{c}}(\%)$ & $8.1 \pm 1.0$ & $8.5 \pm 1.0$ & $<0.0001$ \\
\hline $\mathrm{HbA}_{1 \mathrm{c}}(\mathrm{mmol} / \mathrm{mol})$ & $65 \pm 11$ & $69 \pm 11$ & $<0.0001$ \\
\hline $\operatorname{BMI}\left(\mathrm{kg} / \mathrm{m}^{2}\right)$ & $32.4 \pm 5.4$ & $32.0 \pm 5.5$ & 0.009 \\
\hline Insulin use & $600(25.7)$ & $791(44.3)$ & $<0.0001$ \\
\hline Metformin use & $1,407(60.3)$ & $1,099(61.5)$ & 0.4 \\
\hline Thiazolidinedione use & $444(19.0)$ & $372(20.8)$ & 0.2 \\
\hline Sulfonylurea use & $1,257(53.9)$ & $861(48.2)$ & 0.0003 \\
\hline Meglitinide use & $47(2.0)$ & $37(2.1)$ & 0.9 \\
\hline$\alpha$-Glucosidase inhibitor use & $9(0.4)$ & $20(1.1)$ & 0.005 \\
\hline \multicolumn{4}{|l|}{ At transition } \\
\hline Age (years) & $66.1 \pm 6.6$ & $65.3 \pm 7.0$ & $<0.0001$ \\
\hline Diabetes duration (years) & $13.5 \pm 7.6$ & $15.8 \pm 8.0$ & $<0.0001$ \\
\hline $\mathrm{HbA}_{1 \mathrm{c}}(\%)$ & $5.9 \pm 0.3$ & $7.3 \pm 0.9$ & $<0.0001$ \\
\hline $\mathrm{HbA}_{1 \mathrm{c}}(\mathrm{mmol} / \mathrm{mol})$ & $41 \pm 3$ & $56 \pm 10$ & $<0.0001$ \\
\hline $\operatorname{BMI}\left(\mathrm{kg} / \mathrm{m}^{2}\right)$ & $33.3 \pm 6.1$ & $33.6 \pm 6.2$ & 0.1 \\
\hline Total daily insulin dose $(\mathrm{U} / \mathrm{kg})^{\mathrm{b}}$ & $0.4 \pm 0.4$ & $0.7 \pm 0.6$ & $<0.0001$ \\
\hline Metformin use & $1,900(81.4)$ & $1,324(74.1)$ & $<0.0001$ \\
\hline Thiazolidinedione use & $1,489(63.8)$ & $846(47.4)$ & $<0.0001$ \\
\hline Secretagogue use & $1,541(66.1)$ & $1,043(58.4)$ & $<0.0001$ \\
\hline Acarbose use & $333(14.3)$ & $290(16.2)$ & 0.08 \\
\hline Incretin mimetic use & $355(15.2)$ & $270(15.1)$ & 0.9 \\
\hline
\end{tabular}

was $\geq 6.5 \%$, the 2,333 who achieved an $\mathrm{HbA}_{1 \mathrm{c}}$ before transition of $<6.5 \%$ were more likely to be male, older and have shorter-duration diabetes, and have access to a certified diabetes educator (CDE) at their investigative site at baseline. Prior to initiating intensive therapy at the time of randomisation, this group also had lower $\mathrm{HbA}_{1 \mathrm{c}}$ levels and less use of insulin, but greater use of sulfonylureas and a higher BMI. At the pre-transition visit, they continued to require less insulin, but were more likely to be taking other glucose-lowering medications, including metformin, thiazolidinediones and secretagogues, than those who did not achieve an $\mathrm{HbA}_{1 \mathrm{c}}<6.5 \%$ during intensive management.

These 4,119 participants were followed for a mean \pm SD of $1.1 \pm 0.2$ years (range $0.4-1.4$ ) after their glycaemic management approach was relaxed to the standard glycaemic approach. At the time of the final visit, 711 participants continued to have an $\mathrm{HbA}_{1 \mathrm{c}}<6.5 \%, 1,622$ had a rise from $<6.5 \%$ to $\geq 6.5 \%, 112$ participants had a fall from $\geq 6.5 \%$ to $<6.5 \%$, and 1,674 maintained an $\mathrm{HbA}_{1 \mathrm{c}} \geq 6.5 \%$. Among the 823 participants with a final $\mathrm{HbA}_{1 \mathrm{c}}<6.5 \%$, mean $\mathrm{HbA}_{1 \mathrm{c}}$ was $6.0 \pm 0.3 \%(42 \pm 3 \mathrm{mmol} / \mathrm{mol})$, and among those with a final $\mathrm{HbA}_{1 \mathrm{c}} \geq 6.5 \%$, the mean was $7.7 \pm 1.1 \%(61 \pm$ $12 \mathrm{mmol} / \mathrm{mol})$. More participants whose final $\mathrm{HbA}_{1 \mathrm{c}}$ was $<6.5 \%$ had lost weight and reduced their dose of insulin and use of secretagogues and acarbose from the pre-transition visit to the final post-transition visit compared with those who did not achieve a final $\mathrm{HbA}_{1 \mathrm{c}}$ of $<6.5 \%$ (Table 2).

Achieving a pre-transition $\mathrm{HbA}_{1 \mathrm{c}}<6.5 \%$ was a strong predictor of maintaining a final $\mathrm{HbA}_{1 \mathrm{c}}<6.5 \%$ (crude RR 4.9 [95\% CI 4.0, 5.9], $p<0.0001$ ) (Fig. 1). This strong association was maintained even after adjustment for age, sex, diabetes duration, availability of a CDE at the study site, allocation to intensive blood pressure control, allocation to receive fibrate, pre-randomisation $\mathrm{HbA}_{1 \mathrm{c}}$, BMI and glucose-lowering medication use, and pre-transition BMI and glucose-lowering medication use (RR 4.0 [95\% CI 3.3, 5.0], $p<0.0001)$. Adjustment for change in both BMI and glucose-lowering medication use 
Table 2 Changes in BMI and medication use from the last pre-transition visit to study completion

\begin{tabular}{|c|c|c|c|c|}
\hline Characteristic & Change from pre-transition to final & $\begin{array}{l}\text { Final achieved } \mathrm{HbA}_{1 \mathrm{c}} \\
<6.5 \%(n=823)\end{array}$ & $\begin{array}{l}\text { Final achieved } \mathrm{HbA}_{1 \mathrm{c}} \\
\geq 6.5 \%(n=3,296)\end{array}$ & $p$ value \\
\hline \multirow[t]{3}{*}{ BMI } & $\geq 3 \%$ increase & $115(14.0)$ & $570(17.3)$ & \multirow{3}{*}{$<0.0001$} \\
\hline & Between $-3 \%$ and $+3 \%$ & $379(46.1)$ & $1,697(51.5)$ & \\
\hline & $\geq 3 \%$ decrease & $329(40.0)$ & $1,029(31.2)$ & \\
\hline \multirow[t]{3}{*}{ Insulin dose } & $\geq 15 \%$ increase $^{\mathrm{a}}$ & $51(6.2)$ & $624(18.9)$ & \multirow{3}{*}{$<0.0001$} \\
\hline & Between $-15 \%$ and $+15 \%{ }^{\mathrm{b}}$ & $464(56.4)$ & $1,681(51.0)$ & \\
\hline & $\geq 15 \%$ decrease $\mathrm{e}^{\mathrm{c}}$ & $308(37.4)$ & $991(30.1)$ & \\
\hline Metformin & $\begin{array}{l}\text { Added/continued } \\
\text { Never prescribed/discontinued }\end{array}$ & $\begin{array}{l}585(71.1) \\
238(28.9)\end{array}$ & $\begin{array}{l}2,423(73.5) \\
873(26.5)\end{array}$ & 0.2 \\
\hline Thiazolidinedione & $\begin{array}{l}\text { Added/continued } \\
\text { Never prescribed/discontinued }\end{array}$ & $\begin{array}{l}211(25.6) \\
612(74.4)\end{array}$ & $\begin{array}{l}888(26.9) \\
24.8(73.1)\end{array}$ & 0.4 \\
\hline Secretagogue & $\begin{array}{l}\text { Added/continued } \\
\text { Never prescribed/discontinued }\end{array}$ & $\begin{array}{l}334(40.6) \\
489(59.4)\end{array}$ & $\begin{array}{l}1,623(49.2) \\
1,673(50.8)\end{array}$ & $<0.0001$ \\
\hline Acarbose & $\begin{array}{l}\text { Added/continued } \\
\text { Never prescribed/discontinued }\end{array}$ & $\begin{array}{l}28(3.4) \\
795(96.6)\end{array}$ & $\begin{array}{l}233(7.1) \\
3,063(92.9)\end{array}$ & 0.0001 \\
\hline Incretin mimetic & $\begin{array}{l}\text { Added/continued } \\
\text { Never prescribed/discontinued }\end{array}$ & $\begin{array}{l}59(7.2) \\
764(92.8)\end{array}$ & $\begin{array}{l}271(8.2) \\
3,016(91.8)\end{array}$ & 0.3 \\
\hline
\end{tabular}

Values are expressed as $n(\%)$

${ }^{a}$ Includes those who started insulin after transition

${ }^{\mathrm{b}}$ Includes those who were not prescribed insulin at any point before or after transition

${ }^{\mathrm{c}}$ Includes those who discontinued insulin at or after transition

during the post-transition follow-up also did not alter this association (RR 3.9 [95\% CI 3.2, 4.8], $p<0.0001$ ). Duration

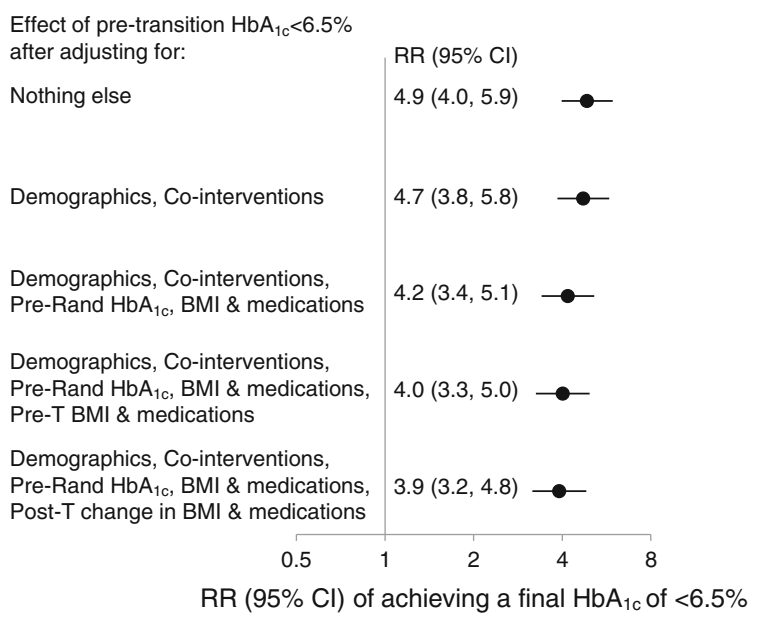

Fig. 1 Effect of having an $\mathrm{HbA}_{1 \mathrm{c}}<6.5 \%(48 \mathrm{mmol} / \mathrm{mol})$ after 4.0 years of intensive diabetes management on the likelihood of having an $\mathrm{HbA}_{1 \mathrm{c}}$ $<6.5 \% 1.1$ years after relaxation of glycaemic management. Demographics $=$ sex, age and diabetes duration; Co-interventions $=\mathrm{CDE}$ availability at study site, randomisation to fibrate and randomisation to intensive blood pressure control; Pre-Rand=at ACCORD baseline prerandomisation; Pre- $\mathrm{T}=$ last pre-transition; Post- $\mathrm{T}=$ post-transition; Pre- $\mathrm{T}$ medications $=$ insulin dose $\left(\mathrm{U} \mathrm{kg}^{-1} \mathrm{day}^{-1}\right)$ and use of thiazolidinedione, metformin, secretagogue, acarbose and incretin mimetic before transition; Post- $\mathrm{T}$ change in $\mathrm{BMI}=$ category of BMI change (as in Table 2); Post- $\mathrm{T}$ change in medications $=$ category of change in insulin dose (as in Table 2) and in use of thiazolidinedione, metformin, secretagogue, acarbose and incretin mimetic from before transition to study completion (added, continued, never prescribed, discontinued) of intensive management was not a significant determinant of final $\mathrm{HbA}_{1 \mathrm{c}}$ (RR 1.05 per year [95\% CI 0.99, 1.12], $p=0.08$ ).

Figure 2 shows that there was no clear threshold for the effect of progressively lower pre-transition $\mathrm{HbA}_{1 \mathrm{c}}$ on the

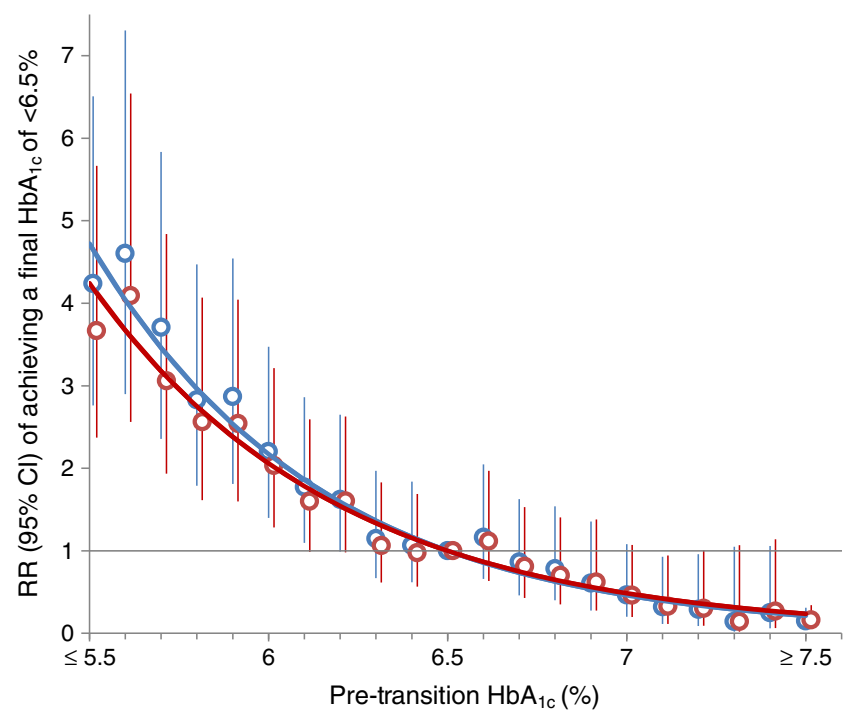

Fig. 2 Prolonged effect of the achieved $\mathrm{HbA}_{1 \mathrm{c}}$ with intensive glycaemic therapy on the likelihood of achieving a final $\mathrm{HbA}_{1 \mathrm{c}}<6.5 \%$. Models are unadjusted (blue circles) and adjusted (for demographics, co-interventions, baseline pre-randomisation $\mathrm{HbA}_{1 \mathrm{c}}$, $\mathrm{BMI}$ and medications, and post-transition change in $\mathrm{BMI}$ and medications) (red circles). The $y$-axis displays risks relative to a pre-transition $\mathrm{HbA}_{1 \mathrm{c}}$ of $6.5 \%$. The lines represent a log-linear model assuming a single linear term for pre-transition $\mathrm{HbA}_{1 \mathrm{c}}$. To convert values for $\mathrm{HbA}_{1 \mathrm{c}}$ in \% into $\mathrm{mmol} / \mathrm{mol}$, subtract 2.15 and multiply by 10.929 
likelihood of achieving an $\mathrm{HbA}_{1 \mathrm{c}}<6.5 \%$ after relaxation of glycaemic management. Indeed, there was a graded relationship such that those with lower pre-transition $\mathrm{HbA}_{1 \mathrm{c}}$ were more likely to maintain an $\mathrm{HbA}_{1 \mathrm{c}}<6.5 \%$ over time. Compared with those with a pre-transition $\mathrm{HbA}_{1 \mathrm{c}}$ equal to $6.5 \%$, those with a pre-transition $\mathrm{HbA}_{1 \mathrm{c}}$ of $6.0 \%$ or $\leq 5.5 \%$ $(37 \mathrm{mmol} / \mathrm{mol})$ were, respectively, 2.2 times [ $95 \%$ CI 1.4 3.5] or 4.2 times [95\% CI 2.8,6.5] more likely to have an $\mathrm{HbA}_{1 \mathrm{c}}$ $<6.5 \%$ at the end of follow-up. Adjustment for age, sex, known diabetes duration, availability of a CDE at the study site, allocation to intensive blood pressure control, allocation to receive fibrate, pre-randomisation $\mathrm{HbA}_{1 \mathrm{c}}$, $\mathrm{BMI}$ and glucose-lowering medication use, and change in both BMI and glucose-lowering medication use during the posttransition follow-up minimally affected these estimates (2.0 [95\% CI 1.3, 3.2] and 3.7 [95\% CI 2.4, 5.7], respectively).

As noted in Fig. 3, there was no relationship between change in $\mathrm{HbA}_{1 \mathrm{c}}$ from pre-transition to the final measurement and the time interval between those two measurements.

\section{Discussion}

Achievement of tight glycaemic control for a mean of 4 years was associated with persistent glycaemic control thereafter. This group of people with a median self-reported duration of diabetes of 10 years had an $\mathrm{HbA}_{1 \mathrm{c}}>7.5 \%$ at baseline, and were intensively managed to a mean of $6.5 \%$ at the time of transition. One-fifth of them had an $\mathrm{HbA}_{1 \mathrm{c}}<6.5 \%$ after a mean of 1.1 years of relaxation from the intensive glycaemic therapy to a standard glycaemic management approach. Those who achieved an $\mathrm{HbA}_{1 \mathrm{c}}<6.5 \%$ during intensive therapy were four times more likely to have a final post-transition $\mathrm{HbA}_{1 \mathrm{c}}$ below $6.5 \%$ compared with those who were not able to achieve such tight control on intensive therapy. This analysis indicates that, in some patients who have established and

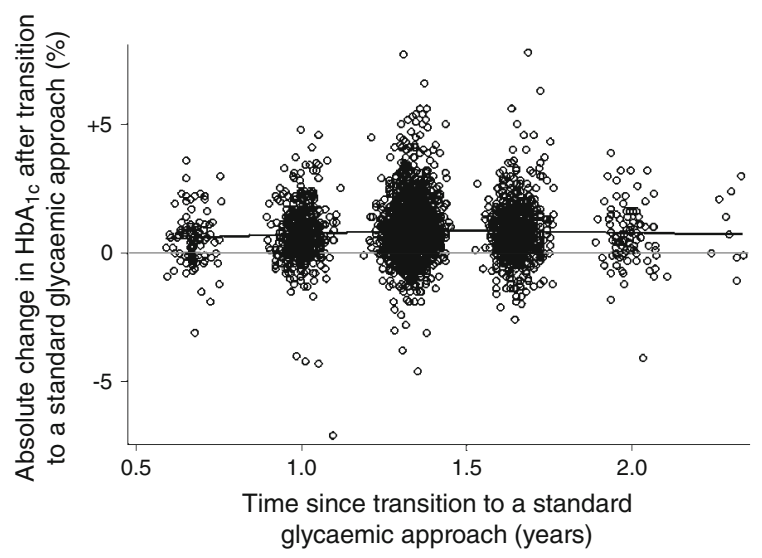

Fig. 3 Effect of time since transition to a standard glycaemic approach on the change in $\mathrm{HbA}_{1 \mathrm{c}}$ since transition. To convert increments for $\mathrm{HbA}_{1 \mathrm{c}}$ in $\%$ into $\mathrm{mmol} / \mathrm{mol}$, multiply by 10.929 initially suboptimally controlled type 2 diabetes, achieving tight glycaemic control with intensive diabetes management is associated with improved maintenance of subsequent glycaemic control despite transition to standard therapy.

There are several potential explanations for the findings, and more than one may have contributed to the observed outcome. First, those who achieved and maintained better glycaemic control may have had physiologically 'milder' diabetes with more beta cell reserve or less insulin resistance at entry into the trial. The group with pre-transition $\mathrm{HbA}_{1 \mathrm{c}}$ $<6.5 \%$ did have shorter known duration of diabetes, and, before initiating intensive management, they had lower $\mathrm{HbA}_{1 \mathrm{c}}$ levels with less insulin use, but more sulfonylurea use and their BMI was higher. Nevertheless, even after adjustment for pre-randomisation and pre-transition characteristics, there was a strong effect of pre-transition $\mathrm{HbA}_{1 \mathrm{c}}$ on posttransition $\mathrm{HbA}_{1 \mathrm{c}}$. Second, despite the fact that the standard glycaemia approach was used to manage intensive group participants after transition, participants may have continued some unmeasured behaviours and therapies that they were using before transition. It is notable that participants who achieved a final $\mathrm{HbA}_{1 \mathrm{c}}<6.5 \%$ did so despite greater downtitration of glucose-lowering medications than those who did not achieve a final $\mathrm{HbA}_{1 \mathrm{c}}<6.5 \%$. These lifestyle changes and decrease in medication use may have led to more weight loss after transition which reduced insulin resistance, allowing their endogenous insulin to be more effective.

Another possibility is that the period of intensive glycaemic control with multiple agents which resulted in near-normal glycaemia may have 'rested' the beta cells and allowed a sustained recovery of beta cell function and/or mass leading to improved glucose homeostasis. Indeed, very early in the course of type 2 diabetes, there is supportive evidence for restoration of glucose homeostasis to the point of remission of diabetes for up to 2 years after 2-6 weeks of intensive management using insulin [6] or oral agents (gliclazide and metformin) [16]. In more longstanding diabetes, short-term continuous subcutaneous insulin infusion [17] and intensive lifestyle intervention [7] have had significant but modest effects. Furthermore, trials in people with impaired fasting glucose and/or impaired glucose tolerance have shown that diabetes can be prevented and/or normal glucose tolerance restored after several years of treatment with therapies that reduce the need to secrete insulin including lifestyle intervention, metformin [18, 19], thiazolidinediones [20, 21], acarbose [22] and insulin [23]. In the present study, this paradigm of therapeutic near-normalisation of glucose is extended to a population with longstanding diabetes using an intensive combination therapy approach. Moreover, this study shows that the nearer to normal that glycated haemoglobin can be brought initially, the more likely sustained maintenance of glucose homeostasis is to be, and this is not simply because it takes longer for $\mathrm{HbA}_{1 \mathrm{c}}$ to drift up from lower levels. 
The role of each of the medications used cannot be established in this study. Greater use of metformin, thiazolidinediones and secretagogues was associated with better pre-transition glycaemic control. However, in multivariable regression models, none of the medications or changes in medication was favourably associated with lower posttransition $\mathrm{HbA}_{1 \mathrm{c}}$ (data not shown). Furthermore, adjustment for medications or changes therein did not affect the relationship between pre-transition and post-transition $\mathrm{HbA}_{1 \mathrm{c}}$, suggesting the types of medications used may be less important than the glycaemic target.

This post hoc analysis was not part of the ACCORD protocol, and must be interpreted with caution. However, the observation is consistent with the existing literature [2-7]. Additional limitations include the absence of a comparison group that did not relax glycaemic management. Nonetheless, both the intensive phase and the relaxation to a standard approach were conducted according to a structured protocol, and information about important covariates was systematically collected for all the 4,119 participants over the full intensive intervention period and the relatively long post-transition follow-up to allow adjustment for potential confounders. Finally, the postulated protection of beta cell function cannot be directly confirmed because of lack of physiological measurements in the ACCORD population.

Questions remain about the optimal duration and type of therapy, and the best candidate patients for this approach, especially in light of the ACCORD Trial finding of increased mortality in the intensive management group [10]. Of note, however, the subgroup of intensively treated participants that benefited here (those who achieve an $\mathrm{HbA}_{1 \mathrm{c}}<6.5 \%$ ) did not have an increased risk of mortality in the ACCORD Trial [24]. The potential benefits and harms of maintaining an $\mathrm{HbA}_{1 \mathrm{c}}$ $<6.5 \%$ despite relaxing therapy to target a higher $\mathrm{HbA}_{1 \mathrm{c}}$ are unknown.

In summary, the results show that attainment of $\mathrm{HbA}_{1 \mathrm{c}}$ levels below the diabetes threshold level of $6.5 \%$ during a mean 4 year period of intensive glycaemic control using a combination of agents is associated with subsequent durable glycaemic control. The relative contributions from physiological vs behavioural changes remain unknown, but the main observation is consistent with other lines of evidence suggesting that the progressive deterioration in glucose homeostasis is not necessarily irreversible in people with established type 2 diabetes.

Funding The ACCORD Trial was supported by grants (N01-HC95178, N01-HC-95179, N01-HC-95180, N01-HC-95181, N01-HC95182, N01-HC-95183, N01-HC-95184, IAA-Y1-HC-9035 and IAAY1-HC-1010) from the National Heart, Lung, and Blood Institute, by other components of the National Institutes of Health, including the National Institute of Diabetes and Digestive and Kidney Diseases, the National Institute on Aging, and the National Eye Institute, by the Centers for Disease Control and Prevention, and by General Clinical Research Centers. The following companies provided study medications, equipment, or supplies: Abbott Laboratories, Amylin Pharmaceutical, AstraZeneca, Bayer HealthCare, Closer Healthcare, GlaxoSmithKline, King Pharmaceuticals, Merck, Novartis, Novo Nordisk, Omron Healthcare, Sanofi-Aventis and Schering-Plough.

Duality of interest ZP has received honoraria for speaking and consulting, and research funds from AstraZeneca, Boehringer Ingelheim, Bristol Myers Squibb, Eli Lilly, Janssen, Merck, NovoNordisk, Roche and Sanofi. MCR has received honoraria for speaking from Sanofi, for consulting from AstraZeneca, Eli Lilly, Eclelyx, Sanofi and Valeritas, and research support from AstraZeneca, Eli Lilly, NovoNordisk and Sanofi. These dualities of interest have been reviewed and managed by Oregon Health \& Science University. FI-B has grants from NovoNordisk and NIH. RMB has served on a scientific advisory board, consulted or performed clinical research with Abbott Diabetes Care, Bayer, Becton Dickinson, Boehringer, Ingelheim, Bristol-Myers Squibb/AstraZeneca, Intuity, Calibra, Dexcom, Eli Lilly, Halozyme, Helmsley Trust, Hygieia, Johnson \& Johnson, Medtronic, Merck, NIH, Novo Nordisk, ResMed, Roche, Sanofi and Takeda. His employer, non-profit Park Nicollet Institute, contracts for his services and no personal income goes to RMB. He has inherited Merck stock. He has been a volunteer for ADA and JDRF. IH has received honoraria for speaking and consulting, and research funds from AstraZeneca/Bristol-Myers Squibb, Eli Lilly, Merck and Novo Nordisk, honoraria for consulting and research funds from Janssen-Ortho/Johnson \& Johnson and Sanofi, and honoraria for consulting from Boehringer Ingelheim. JFL has received honoraria for consulting from Dexcom, Takeda, Valeritas and Vivus. AS has a research grant from NovoNordisk. HCG has received honoraria for speaking and consulting, and research funds from Boehringer Ingelheim, Bristol Myers Squibb, Eli Lilly, GSK, NovoNordisk, Roche and Sanofi. All other authors declare that there is no duality of interest associated with their contribution to this manuscript.

Contribution statement HCG, DLS and MEM designed the study. MEM analysed the data. All coauthors contributed to data collection and/ or interpretation. ZP and HCG drafted the manuscript and all other coauthors provided critical revisions. All coauthors approved the final version. ZP is responsible for the integrity of the work as a whole.

\section{References}

1. U.K. Prospective Diabetes Study Group (1995) U.K. Prospective Diabetes Study 16. Overview of 6 years' therapy of type II diabetes: a progressive disease. Diabetes 44:1249-1258

2. Ikramuddin S, Korner J, Lee WJ et al (2013) Roux-en-Y gastric bypass vs intensive medical management for the control of type 2 diabetes, hypertension, and hyperlipidemia: the Diabetes Surgery Study randomized clinical trial. JAMA 309:2240-2249

3. Mingrone G, Panunzi S, de Gaetano A et al (2012) Bariatric surgery versus conventional medical therapy for type 2 diabetes. N Engl J Med 366:1577-1585

4. Kashyap SR, Bhatt DL, Wolski K et al (2013) Metabolic effects of bariatric surgery in patients with moderate obesity and type 2 diabetes: analysis of a randomized control trial comparing surgery with intensive medical treatment. Diabetes Care 36:2175-2182

5. Bradley D, Conte C, Mittendorfer B et al (2012) Gastric bypass and banding equally improve insulin sensitivity and beta cell function. J Clin Invest 122:4667-4674

6. Kramer CK, Zinman B, Retnakaran R (2013) Short-term intensive insulin therapy in type 2 diabetes mellitus: a systematic review and meta-analysis. Lancet Diabetes Endocrinol 1:28-34 
7. Gregg EW, Chen H, Wagenknecht LE et al (2012) Association of an intensive lifestyle intervention with remission of type 2 diabetes. JAMA 308:2489-2496

8. Wajchenberg BL (2007) Beta-cell failure in diabetes and preservation by clinical treatment. Endocr Rev 28:187-218

9. Mudaliar S (2013) Choice of early treatment regimen and impact on beta-cell preservation in type 2 diabetes. Int J Clin Pract 67:876-887

10. Gerstein HC, Miller ME, Byington RP et al (2008) Effects of intensive glucose lowering in type 2 diabetes. N Engl J Med 358:2545-2559

11. Gerstein HC, Miller ME, Genuth S et al (2011) Long-term effects of intensive glucose lowering on cardiovascular outcomes. N Engl J Med 364:818-828

12. Buse JB, Bigger JT, Byington RP et al (2007) Action to Control Cardiovascular Risk in Diabetes (ACCORD) trial: design and methods. Am J Cardiol 99:21i-33i

13. Gerstein HC, Riddle MC, Kendall DM et al (2007) Glycemia treatment strategies in the Action to Control Cardiovascular Risk in Diabetes (ACCORD) trial. Am J Cardiol 99:34i-43i

14. Gillett MJ (2009) International Expert Committee report on the role of the A1c assay in the diagnosis of diabetes: Diabetes Care 32:13271334. Clin Biochem Rev 30:197-200

15. Eilers PHC, Marx BD (1996) Flexible smoothing with B-splines and penalties. Stat Sci 11:89-121

16. Weng J, Li Y, Xu W et al (2008) Effect of intensive insulin therapy on beta-cell function and glycaemic control in patients with newly diagnosed type 2 diabetes: a multicentre randomised parallel-group trial. Lancet 371:1753-1760
17. Park S, Choi SB (2003) Induction of long-term normoglycemia without medication in Korean type 2 diabetes patients after continuous subcutaneous insulin infusion therapy. Diabetes Metab Res Rev 19:124-130

18. Pan XR, Li GW, Hu YH et al (1997) Effects of diet and exercise in preventing NIDDM in people with impaired glucose tolerance. The Da Qing IGT and Diabetes Study. Diabetes Care 20:537-544

19. Knowler WC, Barrett-Connor E, Fowler SE et al (2002) Reduction in the incidence of type 2 diabetes with lifestyle intervention or metformin. N Engl J Med 346:393-403

20. DeFronzo RA, Tripathy D, Schwenke DC et al (2011) Pioglitazone for diabetes prevention in impaired glucose tolerance. N Engl J Med 364:1104-1115

21. Gerstein HC, Yusuf S, Bosch J et al (2006) Effect of rosiglitazone on the frequency of diabetes in patients with impaired glucose tolerance or impaired fasting glucose: a randomised controlled trial. Lancet 368:1096-1105

22. Chiasson JL, Josse RG, Gomis R, Hanefeld M, Karasik A, Laakso M (2002) Acarbose for prevention of type 2 diabetes mellitus: the STOP-NIDDM randomised trial. Lancet 359:2072-2077

23. Gerstein HC, Bosch J, Dagenais GR et al (2012) Basal insulin and cardiovascular and other outcomes in dysglycemia. N Engl J Med 367:319-328

24. Riddle MC, Ambrosius WT, Brillon DJ et al (2010) Epidemiologic relationships between $\mathrm{A} 1 \mathrm{C}$ and all-cause mortality during a median 3.4-year follow-up of glycemic treatment in the ACCORD trial. Diabetes Care 33:983-990 